\title{
HLA antigens and antinuclear antibody titres in juvenile chronic iridocyclitis
}

\author{
SHIGEAKI OHNO, DEVRON H. CHAR, SAMUEL J. KIMURA, AND \\ G. RICHARD O'CONNOR
}

From the Department of Ophthalmology and the Francis I. Proctor Foundation, University of California, San Francisco, California 94143

SUMMARY HLA antigen frequencies and antinuclear antibody titres were studied in 43 patients with juvenile chronic iridocyclitis. We did not detect an increased incidence of HLA-B27 in patients having chronic iridocyclitis associated with juvenile rheumatoid arthritis or in patients with 'chronic iridocyclitis in young girls'. Both groups of patients had a statistically significant increased incidence of antinuclear antibodies. However, these antibodies were detected more frequently in patients with chronic iridocyclitis associated with JRA than in patients with 'chronic iridocyclitis in young girls'.

Approximately $15 \%$ of children with juvenile rheumatoid arthritis (JRA) develop chronic iridocyclitis (Chylack et al., 1975). Most of the patients with ocular involvement are female and have the pauciarticular form of JRA (Key and Kimura, 1975). Similar ocular findings are observed in the syndrome known as 'chronic iridocyclitis in young girls'. However, these patients do not have inflammatory joint disease or any other identifiable illness (Perkins, 1966). Some investigators have observed a significantly increased prevalence of HLA-B27 and elevated antinuclear antibody titres among patients with juvenile rheumatoid arthritis (Rachelefsky et al., 1974; Schaller et al., 1974; Buc et al., 1974; Edmonds et al., 1974; Rahi et al., 1976). We have studied a group of young patients with chronic iridocyclitis to determine whether a specific HLA antigen pattern or an elevation of the titre of antinuclear antibody was of diagnostic or prognostic importance in this disease entity.

\section{Methods}

Twenty-three patients with chronic iridocyclitis associated with juvenile arthritis were examined in the Uveitis Survey Clinic of the University of

This study was supported in part by a Fight for Sight Grant G574 and by National Institutes of Health Grants EYO1759 and EYO1597. Dr Ohno is a George and Rosalie Hearst Fellow, Department of Ophthalmology.

Address for reprints: Dr D. H. Char, MD, S-322, Department of Ophthalmology, University of California, San Francisco, California, 94143, USA.
California, San Francisco, in 1976. Three were males, 20 were females, and all the patients fulfilled the criteria for the diagnosis of JRA as set forth by the American Rheumatism Association (Brewer et al., 1973). The uveitis developed in all patients before the age of 16 . Ten per cent of these patients initially presented to our clinic with the diagnosis of chronic anterior uveitis, and only on extensive physical and laboratory examination was the underlying juvenile rheumatoid arthritis diagnosed. Twenty-two of the 23 patients tested had either the monoarticular or pauciarticular form of JRA, and none of the patients had acute systemic illness.

Twenty female patients were examined in 1976 with the diagnosis of "chronic iridocyclitis in young girls'. The mean age of these patients was 13.5 years, and the mean duration of their disease was 4.7 years. As in those patients with chronic iridocyclitis associated with JRA these patients manifested a lowgrade bilateral chronic iridocyclitis with posterior synechiae, calcific band keratopathy, secondary cataract, and glaucoma. However, none of these patients has associated joint disease or other signs of systemic disease.

Seventy-two healthy individuals were also tested as control subjects. Most of these were personnel of the Department of Ophthalmology and of the Francis I. Proctor Foundation.

HLA typing was performed on peripheral blood lymphocytes isolated by the method of Böyum (1968), and microlymphocyte cytotoxicity tests were performed using the two-stage method of Amos (1974). More than 80 highly selected antisera were used to 
determine HLA antigens: A1, A2, A3, A9, A10, A11, A28, A29, AW30, and AW32 at the HLA-A locus; and the HLA-B antigens $5,7,8,12,13,14$, 18, 27, BW15, BW16, BW17, BW22, BW35, and BW40 were also tested.

Antinuclear antibody titres were tested using a standard indirect immunofluorescence technique at a dilution of 1:10. Blood samples positive for ANA were titred at dilutions of $1: 16,1: 64,1: 256,1: 512$, and $1: 1024$.

Statistical analysis was done by the chi-square test for the ANA data and the chi-square test with Yates's correction for the HLA data.

\section{Results}

The HLA antigen frequencies in the patient groups and in the control subjects are presented in Table 1. In the chronic iridocyclitis associated with JRA, HLA-A1, and A9 were slightly decreased, and A2 was slightly increased in the patients, as compared with the controls; however, these differences were not statistically significant. The HLA-B27 antigen was observed in $25 \%$ of patients having the syndrome of 'chronic iridocyclitis in young girls', in $27.7 \%$ of patients with chronic iridocyclitis associated with JRA, and in $6.9 \%$ of normal controls. These differences were also not statistically significant.

Table 2 shows the results of ANA titre determinations. Fifteen of 21 patients with chronic iridocyclitis associated with JRA $(71.4 \%)$ were noted to have positive ANA tests. Six of 19 patients with the syndrome of 'chronic iridocyclitis in young girls' had positive ANA titres $(31.6 \%)$ versus 0 out of 20 normal controls. Thus, both of the patient populations with chronic iridocyclitis had a statistically increased incidence of ANA antibody titres versus the normal control population in $\mathbf{P}<0.0001$ and $P<0.02$, respectively. Patients with chronic iridocyclitis associated with JRA had a statistically significant increased incidence positive of ANA titres versus those patients with the syndrome of 'chronic iridocyclitis in young girls' $\left(\chi^{2}=4.8\right.$, $P<0.03)$. There did not appear to be any correlation between HLA-B27 and ANA titres.

\section{Discussion}

The HLA-B27 antigen was not significantly increased in patients with juvenile chronic iridocyclitis versus control subjects. Rachelefsky et al. (1974) noted that $42 \%$ of 26 patients with JRA had the B27 antigen. Buc et al. (1974) also observed an association between B27 and patients with JRA ( $29 \%$ of 34 patients). In this latter report the B27 antigen
Table 1 Frequency of HLA antigens in juvenile chronic iridocyclitis

\begin{tabular}{|c|c|c|c|c|c|c|}
\hline \multirow[t]{2}{*}{ HLA antigen } & \multicolumn{2}{|c|}{$\begin{array}{c}\text { Controls } \\
(N=72)\end{array}$} & \multicolumn{2}{|c|}{$\begin{array}{l}\text { Chronic } \\
\text { iridocyclitis } \\
\text { associated with } \\
\text { JRA }(N=23)\end{array}$} & \multicolumn{2}{|c|}{$\begin{array}{l}\text { Chronic } \\
\text { iridocyclitis } \\
\text { in young girls } \\
(N=20)\end{array}$} \\
\hline & No. & $\%$ & No. & $\%$ & No. & $\%$ \\
\hline $\begin{array}{l}\text { HLA-A1 } \\
\text { HLA-A2 } \\
\text { HLA-A3 } \\
\text { HLA-A9 } \\
\text { HLA-A10 } \\
\text { HLA-A11 } \\
\text { HLA-A28 } \\
\text { HLA-A29 } \\
\text { HLA-AW30 } \\
\text { HLA-AW32 }\end{array}$ & $\begin{array}{r}20 \\
34 \\
16 \\
18 \\
9 \\
10 \\
4 \\
5 \\
5 \\
7\end{array}$ & $\begin{array}{l}(27 \cdot 8) \\
(47 \cdot 2) \\
(22 \cdot 2) \\
(25 \cdot 0) \\
(12 \cdot 5) \\
(13 \cdot 9) \\
(5 \cdot 6) \\
(6 \cdot 9) \\
(6 \cdot 9) \\
(9 \cdot 7)\end{array}$ & $\begin{array}{r}4 \\
16 \\
5 \\
4 \\
2 \\
3 \\
0 \\
1 \\
0 \\
2\end{array}$ & $\begin{array}{l}(17 \cdot 4) \\
(69 \cdot 6) \\
(21 \cdot 7) \\
(17 \cdot 4) \\
(8 \cdot 7) \\
(13 \cdot 0) \\
(0) \\
(4 \cdot 3) \\
(0) \\
(8 \cdot 7)\end{array}$ & $\begin{array}{r}4 \\
10 \\
4 \\
6 \\
1 \\
3 \\
1 \\
0 \\
1 \\
2\end{array}$ & $\begin{array}{l}(20 \cdot 0) \\
(50 \cdot 0) \\
(20 \cdot 0) \\
(30 \cdot 0) \\
(5 \cdot 0) \\
(15 \cdot 0) \\
(5 \cdot 0) \\
(0) \\
(5 \cdot 0) \\
(10.0)\end{array}$ \\
\hline $\begin{array}{l}\text { HLA-B5 } \\
\text { HLA-B7 } \\
\text { HLA-B8 } \\
\text { HLA-B12 } \\
\text { HLA-B13 } \\
\text { HLA-B14 } \\
\text { HLA-B18 } \\
\text { HLA-B27 } \\
\text { HLA-BW15 } \\
\text { HLA-BW16 } \\
\text { HLA-BW17 } \\
\text { HLA-BW22 } \\
\text { HLA-BW35 } \\
\text { HLA-BW40 }\end{array}$ & $\begin{array}{r}6 \\
18 \\
17 \\
19 \\
3 \\
7 \\
4 \\
5 \\
7 \\
3 \\
6 \\
3 \\
8 \\
10\end{array}$ & $\begin{array}{l}(8 \cdot 3) \\
(25 \cdot 0) \\
(23 \cdot 6) \\
(26 \cdot 4) \\
(4 \cdot 2) \\
(9 \cdot 7) \\
(5 \cdot 6) \\
(6 \cdot 9) \\
(9 \cdot 7) \\
(4 \cdot 2) \\
(8 \cdot 3) \\
(4.2) \\
(11 \cdot 1) \\
(13 \cdot 9)\end{array}$ & $\begin{array}{l}2 \\
4 \\
4 \\
7 \\
0 \\
2 \\
2 \\
5 \\
3 \\
0 \\
1 \\
0 \\
1 \\
3\end{array}$ & $\begin{array}{l}(8 \cdot 7) \\
(17 \cdot 4) \\
(17 \cdot 4) \\
(30 \cdot 4) \\
(0) \\
(8 \cdot 7) \\
(8 \cdot 7) \\
(21 \cdot 7) \\
(13 \cdot 0) \\
(0) \\
(4 \cdot 3) \\
(0) \\
(4 \cdot 3) \\
(13 \cdot 0)\end{array}$ & $\begin{array}{l}3 \\
5 \\
4 \\
4 \\
1 \\
3 \\
3 \\
5 \\
1 \\
0 \\
1 \\
1 \\
3 \\
2\end{array}$ & $\begin{array}{l}(15 \cdot 0) \\
(25 \cdot 0) \\
(20 \cdot 0) \\
(20 \cdot 0) \\
(5 \cdot 0) \\
(15 \cdot 0) \\
(15 \cdot 0) \\
(25 \cdot 0) \\
(5 \cdot 0) \\
(0) \\
(5 \cdot 0) \\
(5 \cdot 0) \\
(15 \cdot 0) \\
(10 \cdot 0)\end{array}$ \\
\hline
\end{tabular}

Table 2 IgG antinuclear antibodies

\begin{tabular}{|c|c|c|}
\hline Group & Positive tests & $\%$ \\
\hline Chronic iridocyclitis associated with JRA & $15 / 21$ & $71 \cdot 4^{*},+$ \\
\hline 'Chronic iridocyclitis in young girls' & $6 / 19$ & $31 \cdot 6+$ \\
\hline Normal controls & $0 / 20$ & 0 \\
\hline
\end{tabular}

$\chi^{2}=19.55, P<0.0001$ (difference between patients with chronic iridocyclitis associated with JRA and normals).

$+x^{2}=5.24, P<0.02$ (difference between patients with "chronic iridocyclitis in young girls' and normals).

$\ddagger \chi^{2}=4.85, P<0.03$ (difference between patients with chronic iridocyclitis associated with JRA and patients with 'chronic iridocyclitis in young girls').

was present almost exclusively in those JRA patients with the polyarticular form of the disease. Edmonds et al. (1974) studied a group of patients with juvenile chronic polyarthritis. They noted that 14 out of the 15 JRA patients who eventually developed ankylosing spondylitis or sacroiliitis had HLA-B27. However, only 4 out of 20 JRA patients without sacroiliitis had this HLA phenotype. As we have observed in this study, previous reports by Nissilä et al. (1975) and Gibson et al. (1975) have also failed to note an association between the B27 antigen and patients with JRA. It is possible that the association between B27 and JRA observed by Rachelefsky $e t$ al. (1974) and Buc et al. (1974) could be due to an 
inclusion in their JRA patient population of some patients with juvenile onset ankylosing spondylitis. We think this is unlikely in our study for three reasons: (1) all of our patients with chronic iridocyclitis associated with JRA had the pauciarticular form of the disease, and it is probable that some of Buc et al.'s (1974) patients with polyarticular involvement may have had juvenile onset ankylosing spondylitis. (2) All of the patients in our study had a chronic low-grade iridocyclitis, whereas patients with ankylosing spondylitis of juvenile onset generally have an acute recurrent iridocyclitis. (3) Nearly $90 \%$ of our patients were females, whereas most of the patients affected by ankylosing spondylitis are males.

In our study it does not appear that the HLA-B27 antigen is associated with the chronic iridocyclitis of JRA or with the syndrome of "chronic iridocyclitis in young girls'. It may, however, be a genetic marker for iridocyclitis associated with juvenile onset ankylosing spondylitis or sacroiliitis. We have noted that in adult patients with iridocyclitis that is associated either with or without ankylosing spondylitis, there appears to be an increased frequency of B27 (unpublished data).

In our current study the incidence of positive ANA titres was significantly increased in juvenile chronic iridocyclitis. Patients carrying the diagnosis of chronic iridocyclitis associated with JRA showed a significantly higher prevalence of positive ANA results than patients with the syndrome of 'chronic iridocyclitis in young girls'. Ninety per cent of patients with the uveitis associated with JRA develop their arthritis first; however, $10 \%$ showed the onset of iridocyclitis with the development of systemic signs of JRA. The average length of followup in the patients with the syndrome of chronic iridocyclitis in young girls was 4.7 years, so we think that the likelihood of these patients developing JRA is probably small. However, even in Perkins's (1966) initial description of this syndrome it was noted that a few patients developed arthritis later on.
Schaller et al. (1974) reported that $30 \%$ of patients with JRA without uveitis had positive ANA tests. The role of ANA in the development of the uveitis and of the arthritis remains obscure. In our study there was a significantly higher prevalence of positive tests for ANA among patients with JRA than among patients with 'chronic iridocyclitis in young girls'. It is possible that the risk of developing JRA among the patients with the syndrome of "chronic iridocyclitis in young girls' may be predicted by the presence of a positive ANA test. An alternative suggestion is that positive tests for ANA may be helpful in predicting which patients with juvenile rheumatoid arthritis will develop chronic iridocyclitis.

\section{References}

Amos, D. B. (1974). National Institutes of Health Bulletin, 23. Böyum, A. (1968). Scandinavian Journal of Clinical and Laboratory Investigation, 21, Suppl. 97, 31.

Brewer, E. J., Bass, J. C., Cassidy, J. T., Duran, B. S., Fink, C. W., Jacobs, J. D., Markowitz, M., Reynollds, W. E., Schaller, J., Stillman, J. S., and Wallace, S. L. (1973). Bulletin on Rheumatic Diseases, 23, 712.

Buc, M., Nyulassy, S., Stefanovic, J., Michalko, J., and Mozolova, D. (1974). Tissue Antigens, 4, 395.

Chylack, L. T., Bien Fang, D. C., Bellow, A. R., Stillman, J. S. (1975). American Journal of Ophthalmology, 79, 1026.

Edmonds, J., Morris, R. I., Metzger, A. L., Bluestone, R., Terasaki, P. I., Ansell, B., and Bywaters, E. G. L. (1974). Annals of the Rheumatic Diseases, 33, 289.

Gibson, D. J., Carpenter, C. B., Stillman, J. S., and Schur, P. (1975). New England Journal of Medicine, 293, 636.

Key III, S. N., and Kimura, S. J. (1975). American Journal of Ophthalmology, 80, 425.

Nissilä, M., Elomaa, L., and Tülikainen, A. (1975). New England Journal of Medicine, 292, 430.

Perkins, E. S. (1966). British Journal of Ophthalmology, 50, 169.

Rachelefsky, G., Terasaki, P. I., Katz, R., and Stiehm, E. R. (1974). New England Journal of Medicine, 290, 892.

Rahi, A. H. S., Holborow, E. J., Perkins, E. S., Gungen, Y. Y., and Dinning, W. J. (1976). Transactions of the Ophthalmological Society of the United Kingdom, 96, 113.

Schaller, J. G., Johnson, G. D., Holborow, E. J., Ansell, B. M., and Smiley, W. K. (1974). Arthitis and Rheumatism, 17, 409. 